\title{
Cultivating a New Normal: Mood Disorders in the DSM-III to -5 Era
}

\author{
Adam Dylan Hefty
}

The post-World War II to the present period has seen several large, successive shifts in the categorization and treatment of depression, both as a set of specialized areas within psychology and psychiatry and as a generalized problematic in society. Depression in particular and the larger rubric into which it was absorbed, the management of ostensibly disordered but commonplace everyday moods, attentiveness, and anxiety has reverberated in many social areas, including family life, schooling, and labor and working life. This paper will examine the emergence of the category of the mood disorder as an umbrella category including depression and the treatment of normal-range conditions in contemporary psychiatry and psychology. Instead of pathologization and the treatment of depression as an abnormality which characterized the modern reception of melancholia, "the domain of the exceptional human being" according to Alain Ehrenberg (218), the second half of the $20^{\text {th }}$ century has democratized depression and other mood, attention, and anxiety disorders as a new normalcy: disordered but commonplace conditions which need to be managed in order to achieve optimum productivity, assertiveness, and affective engagement. This conceptual shift accompanies a sharp rise in the prevalence of these states, their diagnosis, or both.

The condition of depression has exploded into social centrality on several fronts. The World Health Organization ranks depression in the top five causes of the global burden of disease and expects it to rise to second place in this ranking within the next 20 years (Blazer 3). The lifetime frequency of moderate to severe depression is around $20 \%$, and at any given time, frequency rates for depressive symptoms such as feeling sad for most of the day are even higher (20). As Horwitz and Wakefield note, "for the past several decades, each successive birth cohort has reported more depressive disorders than previous generations showed" (4). Absolute numbers and percentages of the population in treatment for depression in the US have grown explosively (Horwitz and Wakefield 4). Antidepressant medications, chiefly selective serotonin re-uptake inhibitors (SSRIs) like Prozac and Paxil, are the second most commonly prescribed class of medication by prescription and are in the seventh position by spending (IMS Institute for Healthcare Informatics). 
How to interpret these high rates of depression is another question. Michael Norden argues that our lifestyle, environment, and cultural evolution, especially over the last 100 years, have exacerbated stresses that have led to an epidemic of depression and that we live in "serotonindepleting times" (11). Norden's cure is individualist; most of us, he suggests, could benefit from boosting our serotonin, even if we don't meet the diagnostic criteria for depression. A popular graphic circulated in the aftermath of the Occupy movement posed this as a political problem instead: "Feeling Sad and Depressed? Are you Anxious? Worried about the future? Feeling isolated and alone? You might be suffering from capitalism" (Diogenes of Sinope). Some studies suggest that only onethird of people who suffer from major depression seek treatment, that people who seek wait on average ten years to do so, and that many of those who seek treatment receive inadequate care (Mental Health America).

On the other hand, several critics both from inside and outside the field of psychiatry feel that what we have is an explosion in the diagnosis and treatment of depression rather than any change in an underlying sociomedical phenomenon. Allan Horwitz and Jerome Wakefield are prominent exponents of this idea:

We argue that the recent explosion of putative depressive disorder, in fact, does not stem primarily from a real rise in this condition. Instead, it is largely a product of conflating the two conceptually distinct categories of normal sadness and depressive disorder and thus classifying many instances of normal sadness as mental disorders (6).

It's difficult to evaluate this argument in part because there is no clear baseline for rates of actual depression in past historical moments. Melancholia and depression have been stigmatized conditions throughout most of the history of modernity for most populations, even though a more positive notion of melancholia, tied to creativity and wisdom, has sometimes been applied to intellectuals and artists. Humane treatment for depression was never very widely available before the late $20^{\text {th }}$ century unless one had both available money and available time; for the poor, the asylum was a pathologizing institution of last resort. If rates of depression appear to be higher today than ever before, part of the reason may lie in a lack of successful human adaptation to the exigencies of late capitalism, part may lie in changing diagnostic categories that classify a larger portion of the ongoing human experience as depression, and part may lie in a change from historic underreporting due to stigmatization and lack of available care. Media and cultural attention to depression as a problem today may also encourage people to interpret their experiences in the framework of depression, when they might not have done so in a previous era in which depression was not only less discussed but stigmatized. 
In contemporary discourses of depression ranging from psychiatry to popular self-care to critical theory, mood emerges as a central analytical category which needs to be put into relationship with contemporary affect theory, other analytic categories such as structure of feeling, and apparently distinct diagnostic categories such as attention and initiative.

Silvan Tomkins's theory of affects, introduced into critical theory by Eve Sedgwick, views affects as the simple building blocks of feeling with a biological base. Proponents of the Spinoza-Deleuze-Brian Massumi tradition are careful to stress the differences between affect and emotion; they define affect as a prepersonal exchange of intensity that passes from one body to another and involves an enhancement or reduction of the second body's ability to act. In psychology, it is common to understand "affect" as the external projection as observed by others of an internal feeling. In fact, the term "mood disorder" in the DSM was chosen after an initial proposal of "affective disorder," with the understanding that the former referred more to internal states, the latter more to states as they were observed externally.

I also use the term "affective structures" in a similarly pretheoretical or in medias theoretical sense which can be seen as relating back to Raymond Williams's notion of "structures of feeling." Williams's notion might be said to be a more materialist, instantiated or striated version of the old zeitgeist or "spirit of the age." In this paper, I view depression as an affective structure which is articulated in different ways whether we are talking about pathology and nosology, a profusion of techniques for managing it, or how it is experienced by different individuals and in different culturally and historically defined social groups. Depression can appear as a completely individualized disorder, as a component of generalizations or stereotypes about populations, or as shifting but broad, maladies of the age which serve a hermeneutic function in relation to a given historical conjuncture. At times they are pathologized or medicalized within particular discourses of psychiatry or medicine, and at times the experience of these conditions or common-sense understandings of them do not fit with or escape these knowledge structures of expertise and pathology.

Both mood and the mood disorder seem to fit with this broad sense of the affective but also to sit at cross purposes with it in some respects. Social psychologist Joseph Forgas defines moods as "low-intensity, diffuse and relatively enduring affective states without a salient antecedent cause and therefore little cognitive content," and observes that "moods, even though less intense [than emotions], will often have a more insidious and enduring influence on people's thinking and behaviors" (172). The modern notion of a mood as "a prevailing but temporary state of mind or feeling" seems to have originally applied mainly to anger, grieving, or 
collective or impersonal moods such as the "mood of the crowd" or the "moods of nature" (OED "mood"). The sense of mood as a ubiquitous, variegated set of states for each individual seems to be a much more modern sensibility. Even the Oxford English Dictionary's first citation for mood in the generic sense of "bad mood" does not appear until 1929. Along with Forgas's intuition that there is something "insidious" about mood, I will note that already in this sense of the ubiquity of moods there is something about them which seems unruly and in need of management. Anger and grieving are traditionally understood as normal emotional states which pass after a period of time, both of which have the potential to become disordered or excessive to what is considered socially and culturally proper. The notion that an individual is always subject to some kind of mood suggests that there is a constant succession of conditions which, like anger or grieving, are normal emotional conditions but which have the potential of being disordered or excessive, and therefore should be surveilled and possibly managed by the well-disciplined individual.

Emily Martin points out that DSM descriptions of mood disorders do not fit squarely with common-sense notions of moods or emotions. For example, the DSM description of major depression cites "depressed mood" but does not necessarily explain what this constitutes or describe any particular mood states, though it mentions "feelings of worthlessness" and "inappropriate guilt" without further description (Martin 44). Martin argues that DSM descriptions of manic depression correspond more closely to "everyday understandings of motivation" than to mood (193). She sees descriptions of depression as involving an absence of motivation and descriptions of mania as involving an excess of motivation. I would add that the symptomatic clusters of the DSM are disarticulated from everyday common sense, involving elements (in the account of depression) of mood, motivation / attention / focus, and somatic symptoms like change in appetite or weight, insomnia or hypersomnia, psychomotor agitation or retardation, etc.

The construct of the mood disorder, an umbrella category including unipolar and bipolar depression and other mood-related conditions like seasonal affective disorder in DSM-IV, is somewhat deemphasized in DSM-5, but the question of mood remains central. The ubiquity of mood as a question in psychiatry, contemporary psychotherapy, and extra-clinical forms of self-care provide a set of culturally available interpretations which change people's experiences of the conditions themselves (Mayes and Horwitz 261). Thus, the idea of a ubiquitous, changing set of individual moods which invite the question of a need for the management of mood / attention / motivation isn't something that is only imposed from institutions of power such as psychiatry, the pharmaceutical industry, and business; it is articulated and 
rearticulated over time as people interpret their lives within and around these categories.

\section{Depression, Mood Disorders, and the DSM}

Beginning with the third edition of the Diagnostic and Statistical Manual of Mental Disorders (DSM-III), which was developed during the mid 1970s and released in 1980, depression has been grouped, along with bipolar and substance abuse disorders, under the then-new category of the mood disorder. DSM-III constituted or initiated a radical paradigm change in the classification and treatment of mental illness. The marketing of SSRIs and the cultural changes that embraced them built off of changes in the conception of depression that were instituted with DSM-III and the notion of a mood disorder. A lot of work has been done that shows the radical nature of DSM-III and some of its implications, but the organizing category of the mood disorder has received less attention. I will argue that defining depression as a mood disorder along with the creation, marketing, and promulgation of techniques for managing mood disorders constitutes a broad, cultural problematic in which mood is a problem to be managed.

The major changes inaugurated by DSM-III include its conception of itself. DSM-I and -II were small, administrative codebooks, rarely used by mental health practitioners, as opposed to DSM-III which is today regarded as the "psychiatric bible" (Mayes and Horwitz 261). Because of this, the revolution of DSM-III took many psychiatrists by surprise. Many political, business, and disciplinary tensions had contributed to the push for a redefinition of psychiatry's diagnostic practices, however, so once the DSM-III revolution was complete it became essentially irreversible.

Under DSM-I and -II, psychiatric conditions were defined in essentially psychodynamic terms deriving ultimately from Freudian theory which saw the roots of most emotional conflict in early childhood experiences and a failure of coping mechanisms which generated neuroses, in the conflict between conscious expectations and intents and unconscious wishes. By the 1970s, psychodynamic theories were still prominent, but a number of other schools of psychiatry with very different frameworks were coming to the fore; one of the most enduringly prominent was behaviorism, which was uninterested in underlying roots of a patient's conflict. One of the motivations for creating DSM-III was to create a theory-neutral guide that could be used by practitioners espousing these many different approaches.

In moving away from the causative theoretical basis of DSM-II, central members of DSM-III's task force including Robert Spitzer and close allies who came out of the psychiatry department at Washington University turned instead to an approach based in the thinking of late $19^{\text {th }}$. 
century German psychiatrist Emil Kraepelin. Mayes and Horwitz cite Allan Young to explain three major tenets of Kraepelin's thought:

that mental disorders are best understood as analogies with physical diseases; that the classification of mental disorders demands careful observation of visible symptoms instead of on inferences based on unproven causal theories; and that empirical research will eventually demonstrate the organic and biochemical origins of mental disorders (cited in Mayes and Horwitz 260).

The neo-Kraepelinian credo came to include some additional elaborations of these beliefs, including:

Psychiatry treats people who are sick and who require treatment for mental illness.

There is a boundary between normal and sick...

There are discrete mental illnesses...

The focus of psychiatric physicians should be particularly on the biological aspects of mental illnesses...

There should be an explicit and intentional concern with diagnosis and classification...

Diagnostic criteria should be codified, and a legitimate and valued area of research should be to validate such criteria by various techniques... (Klerman cited in Lewis 113) ${ }^{1}$

The neo-Kraepelinian "young turks" "replicated the positivistic drive in the behavioral sciences towards operational definitions of concepts" (Mayes and Horwitz 260). While the entire DSM task force voted to modify and soften Spitzer's controversial claim that "mental disorders are a subset of medical disorders" (260) this neo-Kraepelinian thinking significantly shaped DSM-III. This sensibility created a professional, philosophical authority that eventually served to authorize a series of common-sense propositions about depression, such as: depression is a (medical) disease; the basis of depression is biochemical; and depressed individuals have a biochemical imbalance.

In identifying these propositions as contentious, I don't mean to suggest that the opposite is true, and that the biochemical basis of depression is insignificant or unworthy of research or unlikely to be a point of interest in any alleviation of human suffering. Nevertheless, this

\footnotetext{
${ }^{1}$ Klerman's list includes nine points; I've excerpted six of them here, which are relevant for the discussion at hand.
} 
set of propositions has committed society to a view of depression which is one-sided and which tends to close off other important causative factors and approaches to care. The analogy between physical and mental pathologies and the position that there are discrete mental illnesses are quite suspect hypotheses, as I'll argue below. The acceptance of these propositions had consequences in terms of what kinds of mental healthcare are available and how society views the problem; the ascendancy of the biological, medical model has contributed to a decline of social psychology, psychoanalysis, and long-term, psychodynamic therapy ${ }^{2}$ while contributing to the profusion of a range of techniques of self-care and management which have a double-edged nature. On the one hand, many people may be able to use these techniques to alleviate persistent suffering and to lead more satisfying lives. On the other hand, the cultural profusion of these techniques may strongly suggest their general use, so that suffering seems less like a meaningful or acceptable part of the human condition and more like something to "get over" as soon as possible so that one can get on with the task of producing in oneself positive, affiliative, productive affective states.

DSM-III also accompanies changes in psychiatry's relationship with the insurance industry which have implications for diagnostic validity. During the 1960s, insurance companies had begun to cover psychotherapy as a partially reimbursable expense. Though the extent of these reimbursements was small compared to today, insurance companies considered psychotherapy a "financial "bottomless pit" (Mayes and Horwitz 253) and pressed for greater accountability and well-defined diagnoses.

[S] everal of those intimately involved in the design of the DSM-III later acknowledged that the manual's structure was "strongly influenced by the need for diagnoses for which insurance companies could provide reimbursement and that could be reliable for researchers" requesting federal money. (Mayes and Horwitz 262)

The principle of discrete mental illnesses defined as clusters of symptoms fit the Kraepelinian theoretical presupposition of many of the authors of DSM-III, but it also fit with this concern to conform psychiatry to the impulses of the insurance industry.

Partly due to this concern for administrative and insurance clarity, Spitzer and other principle designers of DSM-III placed a premium on reliability, the idea that different clinicians would see the same patient and reach the same diagnosis, over validity, the idea that the diagnostic

\footnotetext{
${ }^{2}$ For analysis of the decline of social psychology in relation to these changes, see Blazer. For the decline of psychoanalysis, see Shorter.
} 
category represents a "true," naturally coherent, existing, discrete disorder entity. Spitzer himself admitted this in the negative; "[T]o the extent that a classification system of psychiatric disorders is unreliable, a limit is placed on its validity for clinical research or administrative use" (cited in Wakefield 241). Priority was to be placed on research needs (including obtaining funding) and administration (including insurance billing), and that meant focusing on reliability. Jerome Wakefield argues that DSM-III sacrifices validity for reliability, arbitrarily excluding from diagnostic criteria any criteria which would necessitate a clinician making a complicated value judgment (Wakefield 242). Wakefield cites the example of the bereavement exception for depression, in which a person is considered depressed if "the disturbance is not a normal reaction to the death of a loved one" (242) He points out that the same kinds of symptoms that happen in response to bereavement happen in response to many other losses,

... such as receiving a terminal medical diagnosis, suffering a disfiguring injury, or having a loved one terminally ill. It seems that the only reason for limiting the exemption to bereavement is that clinicians would otherwise be forced to evaluate the meanings of various real losses in their patients' lives and to assess whether the losses are sufficiently deep to make depressive symptoms part of a normal mourning and adjustment process, which would decrease reliability. (242)

The Loss of Sadness cites this same problem with the depression diagnostic scheme to argue that DSM criteria erroneously medicalize normal sadness. Psychiatrist Bradley Lewis goes even farther:

The validity critique of the manual has been so strong that DSM science scholars (both insiders and outsiders) express serious doubts as to whether there is any meaningful connection between the diagnoses of the DSM and the "real world" of human mental suffering. (Lewis 104)

The category of the mood disorder constitutes a significant shift in the classification of depression. One small part of the initial impetus for DSM-III was to bring the US classification scheme in line with The International Statistical Classification of Diseases (ICD). The ICD uses the term "mood (affective) disorder," and the term "mood disorder" in the DSM was adopted after an original proposal of "affective disorder." ("Mood" was thought to refer to an underlying state, while "affective" was thought to refer to the external expression of this mood observed by others.) One result of the mood disorder scheme is that diagnosing depression now involves a description of symptoms within a rubric rather than an account of a patient's condition that includes not only the patient's 
symptoms but relational and social factors in the patient's life. ${ }^{3}$ The symptoms themselves are enough to establish the patient's disordered state.

Since DSM-III, the DSM has had two full new editions: DSM-IV, published in 1994, and DSM-5 (now identified with an Arabic rather than a Roman numeral), released in May 2013. Both are consistent with the general approach pioneered by DSM-III. Major changes were predicted for DSM-5, but at the level of overall philosophy and diagnostic approach, these changes did not really materialize, though several disorders were reconceptualized. A few changes have affected the diagnoses of depressive disorders. The category of mood disorders has now been divided into two chapters on "Bipolar and Related Disorders" and "Depressive Disorders" (American Psychiatric Association).

Additionally, "DSM-5 contains several new depressive disorders, including disruptive mood dysregulation disorder and premenstrual dysphoric disorder" (American Psychiatric Association). The former diagnosis is intended to move "children up to age 18 years who exhibit persistent irritability and frequent episodes of extreme behavioral dyscontrol" out of the bipolar category; critics have complained that these changes will pathologize tempter tantrums and PMS. The bereavement exclusion from major depressive disorder has been removed from DSM-5, in one of the more controversial changes. Supporters argue that depression following bereavement isn't clearly different from depression following other major losses or, sometimes, depression following no clear loss. They say that depressive complications beyond normal grieving may exacerbate the grieving process, and that clinicians should be able to discern this and provide help without medicalizing normal grief. Detractors argue "that [the bereavement exclusion's] removal will medicalize normal grief; label and stigmatize bereaved people; and lead to harmful, inappropriate, and injudicious use of pharmacologic interventions for normal sadness" (Zisook and Shear).

It's clearly too soon to tell what the impact of DSM-5 will be on mental health and the treatment of depressive disorders in particular, but the trend seems to be in the direction of introducing yet more disorders at the normal end of the spectrum which raise the concern of pathologizing normal loss, developmental stages in life, and cultural differences. This edition of the DSM has received more critical publicity than previous editions, with some psychiatrists calling for an outside review. The National Institute of Mental Health, the primary US government agency that deals with mental health research, announced just before the formal release of DSM-5 in May that it considered the symptomatic clusters

\footnotetext{
${ }^{3}$ See Blazer, 40-41 for a striking pairing of hypothetical diagnostic formulations for a patient with the same complaint seeking care from a psychiatrist in 1963 and 2003.
} 
which constitute DSM diagnoses as basically arbitrary, launching the alternative Research Domain Criteria (RDoC) project (Brauser). A statement from the British Psychological Society went even further, calling for "a paradigm shift away from an outdated disease models, towards one which gives much more weight to service user experience and psychosocial approaches" (British Psychological Society).

\section{Techniques of Mood Management}

To see how the treatment of depression has changed under the category of the mood disorder, we need to look beyond the changes in DSM to see how the introduction of new techniques for managing mood, particularly the new generation of antidepressants beginning with Prozac in 1987, have further contributed to this shift away from treating depression as a relational, social, and biological complex towards a question of mood management. DSM-III created a new paradigm through which mental illness, including depression, was understood. It institutionalized a biological, medical pathology model in which depression was understood as a cluster of symptoms. Diagnostic reliability and administrative clarity for insurance purposes took precedence over correctly analyzing the nature of mental disorder. With psychoanalysis and social psychology pushed to the side, relational and social forces in patients' lives took a back seat to symptom clusters and biochemical balance. But to create a new economy of mood management, a new set of techniques had to be introduced, and some old techniques had to be refurbished.

These techniques include the use of psychotropic pharmaceuticals, psychotherapeutic techniques (some of which, especially cognitivebehavioral therapy [CBT], are often practiced in a short-term, problemsolving mode), and alternative techniques like mindfulness, meditation, yoga, and stress reduction. I use the term "mood management" (which also is used in psychology to refer to individuals' managing their moods using media) to refer to the ensemble of these techniques, all of which are used to treat common quotidian psychological symptoms like mood, anxiety, and attention which are present throughout a variety of disorders and not-yet-medicalized conditions.

The return to neuroscience as a core preoccupation of psychiatry didn't start with Prozac; Edward Shorter sees the current dominance of neurochemistry as reaching back to a resurgence of research in the 1920s, when Otto Loewi isolated the first neurotransmitter, 1930s research which led to the introduction of chlorpromazine (Thorazine) in the 1950s, and benzodiazepines and Valium in the 1960s (Shorter). Widespread psychiatric use of medication was the norm by the late 1970s, spurred in part by psychiatrists' need to treat an influx of deinsitutionalized patients 
who were not responsive to talk therapy (Mayes and Horwitz 255). However, the success of Prozac spurred a new profusion of research into psychotropic pharmaceuticals which continues today, suggesting that Shorter's blunt triumphalism is not completely misplaced: "In the past hundred years psychiatry has come full circle: psychoanalysis lost; medicine won."

Today antidepressants are widely prescribed by primary care doctors - "four out of five prescriptions for psychotropic drugs are written by physicians who aren't psychiatrists" (Smith). This is a bit of an irony, since one of the concerns that led to DSM-III was psychiatrists' concern that their practice was being undermined by an influx of other mental health professionals offering talk therapy at cheaper rates, such as psychologists, social workers, and lay counselors (Mayes and Horwitz 257). While psychiatry has kept its place as the gatekeeper of mental health, psychiatrists do not control the dispensation of psychotropic drugs, though psychiatrists and psychologists worry that primary care doctors may prescribe them improperly in many cases.

A great deal has been written about Prozac and other SSRIs; much of the early literature was extremely optimistic, while the mid-late aughts saw the appearance of more critical pieces. Along with a common concern about the medicalization of sadness and the cultural consequences of trying to deal with negative emotions through taking a pill, concerns have been raised about the efficacy of SSRIs. While SSRIs have more tolerable, less dangerous side effects than the previous generation of antidepressants, such as monoamine oxidase inhibitors (MAOIs) which were developed in the late 1950s, most studies have shown that SSRIs are no more effective than MAOIs, and some studies suggest that MAOIs and electroconvulsive therapy were much more effective (Parker). Some evidence suggests that much of the positive effect of SSRIs as they are actually used comes from the placebo effect (Smith).

Even with the effectiveness of SSRIs and the hegemony of the DSM model in question, use of pharmaceutical antidepressants remains extraordinarily important both economically and culturally, perhaps the most prominent of the new techniques of mood management. Of course in some sense, humans have always altered their moods chemically, but what's new is that this is sanctioned by the medical establishment, that the drugs involved are designed for long-term use and mood stabilization, not just short-term enhancement, and that in many countries these drugs are available to a broad swath of the population at an affordable cost. If melancholia in the $19^{\text {th }}$ century was usually only treated for the few with disposable time and income or in extreme cases involving hospitalization, and depression in the early $20^{\text {th }}$ century was still a stigmatized condition, today, while some of that stigma remains, at the same time a culture of 
confessing about depression has arisen, and today getting an SSRI for depression from a primary care doctor in the US is a democratic experience.

Of course SSRIs and antidepressants more generally are not the only technique of mood management; increasingly, especially with mental health parity laws in the US though also preceding them, insurance plans are paying for some psychotherapy, usually a limited number of visits per year. This means that psychotherapy is available to many more people than had access to it in previous eras. This availability once again is double-edged, since due to insurance and other factors, the kinds of therapy which are available and reimbursable today have changed.

The reasons for this are complex. Psychoanalysis and psychodynamic therapy have suffered a decline for a number of reasons. They rely on hypotheses about the relationship between our conscious mind and unconscious thoughts and wishes, an approach which flies in the face of the disease-oriented, positivist model. Cognitive-behavioral therapy (CBT) in contrast describes itself as "evidence based." Psychoanalysis can take a long time to work, and even then there are no guarantees for the success of a given patient/therapist relationship. CBT holds up the promise of some improvement even in the short term.

Insurance companies in the era of managed care seem to prefer CBT due to its potentially limited nature. Philip Cushman and Peter Gilford argue that the suitability of CBT for the managed care moment goes beyond this. First, managed care descriptions of psychological phenomena tend to be offer simplistic views of psychological disorders, though these are split between a medicalized, biochemical view and an anecdotal, behavioral view (Cushman and Gilford 987). Second, CBT is "particularly helpful in ensuring that the patient complies with treatment recommendations, homework assignments, and other aspects of the therapy that increase the likelihood of a positive outcome" (Tompkins cited in Cushman and Gilford 988). These elements of psychological simplicity and compliance are used to configure the patient, along with "a third element: a belief that symptoms constitute psychological life" (Cushman and Gilford 988). CBT fits well with this aspect of managed care as well, since it is particularly oriented towards symptom-reduction.

Psychoanalysis constitutes a small "market share" of the overall therapeutic world today -1 to $2 \%$ depending on the account (see both Shorter, and Martin and Helmore). However, it remains intellectually important; Ilene Philipson argues that the therapeutic practices of psychoanalysis have changed as well, in what constitutes a significant feminization of the field (Philipson). Psychoanalytic psychotherapists today are much less likely than in the past to be both male and psychiatrists, and the constituency of psychoanalysis has changed its 
gender composition towards a more feminized one as well. Thus, while CBT has introduced a model which is in many ways less relational and more oriented towards the surface manifestations of moods than other forms of therapy, psychoanalysis and psychodynamic therapy have evolved towards a more relational model. Both models have mostly dethroned the traditional therapist as authority figure, but the CBT model tends to see the patient's moods as a project and be a "businesslike" relationship, while contemporary psychoanalytic practice is highly attuned to transference and countertransference in the relationship between therapist and patient.

Much contemporary practice of psychotherapy does not adhere clearly to one of these two major schools of thought which in some sense represent opposite poles of an approach to psychotherapy. Much of the psychotherapy available in the US today uses an integrative, holistic, or eclectic approach involving elements of cognitive-behavioral, psychodynamic, relational, Gestalt, and even somatic therapy as well as approaches deriving from attachment theory. Therapy itself is by no means becoming outmoded, but patients managing their mental health using prescription drugs and no talk therapy is increasingly common: "In 1996, one-third of patients taking antidepressants also received therapy. By 2005, only one-fifth of patients did" (Smith).

Alternative techniques of self-care are becoming increasingly prominent, often tied to the benefits of mood management and stress reduction. While these techniques are "new" in relationship to this kind of use in North America and Western Europe, some of them, like mindfulness, which derives from Buddhist traditions, meditation, and yoga are of course far from new. Many contemporary forms of stress reduction, relaxation, and counseling incorporate elements of these techniques, in clinical, non-clinical, and extra-clinical settings. A great deal has been written about the efficacy and promise of these techniques, over the past 10-15 years, but even in comparison to CBT there is very little critical literature on this subject in relation to other social dynamics. An exception, a 2007 paper by sociologist Kristin Barker, critiques mindfulness as a therapeutic construct for replicating the individualism and personal responsibility ethic of biomedicine despite its "alternative" ethos. Mindfulness also suggests a contradictory relationship with the project of modern self-management:

On the one hand, mindfulness opposes excesses of a rationalized life. On the other hand, mindfulness is a disciplinary practice (Foucault 1977) that brings the level of required surveillance down to an ever smaller increment of time: moment-to-moment or breath-to-breath. (Barker) 
I've emphasized the aspects of the cultural diffusion of techniques of mood management which are imbricated with managementality, both on the job narrowly speaking and writ large in other aspects of society. These techniques also enhance people's autonomy, self-determination, health, and contentment. Some people who could hardly face life's problems and/or their own internal problems without antidepressants take them and find either that they "feel like themselves again" or feel better than they ever did before, however they may define that. Psychotherapy can help people in many different ways, from facing and solving problems that feel insoluble to dealing with deep-seated conflicts and traumas. Yoga and mindfulness techniques can help to integrate body and spirit, and meditation even when used sporadically can have a surprisingly profound, positive somatic impact.

However, we must recognize a double-edged nature to the diffusion of these techniques in the context of late capitalism. They are not becoming widely available due only to society finally casting aside some of the stigmas of mental illness or a beneficent response to a bottom-up popular demand. And though the pharmaceutical industry clearly has a lot to do with the wide availability of psychotropic drugs, they are not the only source driving the cultural availability of these techniques either; in fact there are some cultural trends to break away from over-medication and towards the use of other (short-term therapeutic or alternative) techniques. Overall, we've moved from a form of capitalism that didn't care about most people's moods to one which is extraordinarily concerned with the ability of workers and students to create very particular affective states. The cultural impetus to be able to manage one's mood is a factor in the wide profusion of these techniques, and their broad, cultural effect is marked by this managementality even if they are used in many cases for autonomy- and health-enhancing effects.

\section{The New Normal in Mental Health}

The distinction between the normal and the abnormal or pathological is a key, longstanding organizing principle of both physiological medicine and mental health; it has been a particularly vexing question in the latter arena. The normal / abnormal divide still plays an important role in contemporary psychiatry and mental healthcare, but I will argue that the nature of this divide and what psychology and psychiatry see themselves as treating has shifted significantly. In nosological terms, DSM categories are categories of the abnormal, disorders which put a person's mental or emotional functioning outside of a desired, healthy-functioning norm. Yet the practice not only of the DSM but to some extent of previous, postwar forms of psychiatry as well has been to use these pathologized or medicalized categories increasingly to 
treat people who overall would be considered fairly highly functioning and in that sense "normal," though they might have been considered neurotic by post-WWII psychiatry. The normal gets redefined from an absence of disorder or neurosis to managing disorder or neurosis. Combining these categorical shifts with the widespread availability of mood management techniques and the sense that they ought to be widely available, selfmanagement of one's own moods comes to be understood as a new normal with which psychiatry, psychology, social work, and alternative forms of mental health are concerned. Instead of being concerned with the abnormal, mental health becomes concerned with the fine-tuning of the person towards greater productivity and an optimum normality.

In this schema, the categorization of normal and abnormal persons moves away from the categorization of normal and abnormal states. In the old, abnormal psychology, a person with an abnormal condition was considered to be psychologically abnormal, and this person was alienated, as Foucault argues, in the sense of being treated as an other outside of the domain of reason. States that might be considered either abnormal and psychotic or semi-abnormal and neurotic, like melancholia or hysteria, were generally stigmatized. In contemporary society, the stigmas have not disappeared, but they have slackened, and there is a corresponding profusion of conditions which are diagnostically considered abnormal and are pathologized from a medical standpoint but which go hand-in-hand with being a normal, high-functioning person. Being normal becomes the management of all of one's disordered conditions and the project of resolving them and moving towards an optimum normalcy rather than the absence of disorders.

The tradition of philosophy of science and genealogy of scientific knowledge represented by Foucault and his mentor, Georges Canguilhem, tended to focus on the abnormal as an interpretive key for a given medical or psychological context. Canguilhem argued that understanding the given theory of the abnormal was key for understanding the articulation of a norm:

The abnormal, as ab-normal, comes after the definition of the normal, it is its logical negation. However, it is the historical anteriority of the future abnormal which gives rise to a normative intention. The normal is the effect obtained by the execution of the normative project, it is the norm exhibited in the fact. In the relationship of the fact there is then a relationship of exclusion between the normal and the abnormal. But this negation is subordinated to the operation of negation, to the correction summoned up by the abnormality. Consequently it is not paradoxical to say that the abnormal, while logically second, is existentially first. (Canguilhem 243) 
Canguilhem's description of the existential primacy of the abnormal applies to psychiatry and mental health, since these technologies trace their origin to the asylum, which was exclusively concerned with the abnormal.

Freud is often credited with helping to take psychiatry out of the asylum and into the private clinic; while the move towards the private clinic predates the wide influence of Freud, and was already underway with neurologists, physicians, and psychiatrists treating conditions like neurasthenia (Sicherman 43), the success of psychoanalysis greatly increased the popularity of the private psychiatric clinic and especially the so-called "talking cure." In dealing with people who were well enough (and well-to-do enough) that they did not need to be hospitalized for their conditions, doctors like Beard, Weir Mitchell, and Freud had already taken psychiatry or mental healthcare, still in their infancy, somewhat away from the abnormal of institutionalized insanity and towards normal-range conditions that impaired but did not destroy their clients' ability to function in society. But psychological theory was still concerned largely with the abnormal. Many of Freud's most famous case studies are concerned with individuals who were affected by debilitating conditions which were considered abnormal. Early psychoanalysis seems to conform reasonably well to the Canguilhem model, in which the abnormal is existentially prior even if logically and eventually also practically secondary to normal-range neuroses.

Post-WWII psychiatry took another step towards a concern with normal-range conditions. According to Mayes and Horwitz, this broadening was so extensive that it contributed to worries that psychiatry was too subjective and broad to be a science:

"Postwar psychiatric thinking," the historian Gerald Grob points out, "reflected an extraordinary broadening of psychiatric boundaries and a rejection of the traditional distinction between mental health and mental abnormality" (Grob, 1987, p. 417). The downside of this expansive view of mental illness, however, was that it poorly separated healthy from sick individuals. Between 1900 and about 1970, the focus of dynamic psychiatry broadened from the treatment of neuroses to more generalized maladaptive patterns of behavior, character, and personal problems. Its clients came to be people who were dissatisfied with themselves, their relationships, their careers, and their lives in general. Psychiatry had been transformed from a discipline that was concerned with insanity to one concerned with normality... (Mayes and Horwitz 250) 
The extent to which psychiatry in the 1970s was concerned with normality needs to be tempered somewhat by the class nature of the enterprise:

[I]t appeared that psychotherapists preferred clients who were young, attractive, verbal, intelligent, and successful-what came to be labeled the YAVIS syndrome. Psychotherapy was described as the purchase of friendship. Psychotherapists were accused of creating demands for services from those who were not really ill,

but were merely discontent—-the worried well—and neglecting the more needy. (Kirk and Kutchins 254)

Thus, if psychiatry was concerned largely with the normal rather than the abnormal, and indeed psychiatrists often referred formerly institutionalized patients with more severe problems to psychologists and social workers (Mayes and Horwitz 255), psychiatry was still not concerned with the mental conditions of a broad range of the populous, but those of leading social groups. Insurance reimbursement for psychotherapy was a very new practice in this time period, which only covered a small portion of the total costs, and available antidepressant pharmaceuticals had too many potentially harmful side effects and dangerous interactions with foods for their consumption to become a mass phenomenon. Psychiatry was no longer oriented towards the abnormal, but it had not yet reached its democratic phase.

DSM-III attempted to re-establish a firm dividing line between the normal and the abnormal and to affirm that psychiatry treats the abnormal. Two tenets of the neo-Kraepelinian credo held by the chief framers of DSM-III were, "Psychiatry treats people who are sick and who require treatment for mental illness" and "There is a boundary between normal and sick." Indeed, the maximum program of the neo-Kraepelinians was to treat mental disorders as medical diseases under a positivistic framework. However, this intent cuts against another project which seems to be happening in DSM-III, which is to provide a plausible nosological justification for the wide scope of psychiatry and even to expand that scope further. Thus, the "generalized maladaptive patterns of behavior, character, and personal problems" that were the subject-matter of much of psychiatry in the 1970s were not written out of DSM-III; instead, they were rendered symptomatically and codified as mood disorders, anxiety disorders, attention disorders, etc. Indeed, one criticism levied at DSM-5 is that it has continued to define new disorders that expand the scope of what is considered a mental disorder to include conditions which may describe some aspect of many or most people's daily functioning.

\footnotetext{
${ }^{4}$ See note 1 .
} 
Thus, mental healthcare in the era of DSM-III through -5, SSRIs, and mood management engages in a certain slight of hand in relationship to the normal and the abnormal. It defines quotidian, common behaviors as mental disorders, defines mental disorders as mental illnesses, and treats these as sicknesses which it is the job of psychiatry (and allied fields of mental health) to cure. One could argue that this means that the dividing line of the normal and the abnormal no longer exists for contemporary psychiatry, but this is not quite accurate in at least three senses. First, however this is theorized, there is still in practice a division between how more severe psychoses are treated and how more normal-range conditions of mostly functional / socialized people are treated. Of course, even here the dividing line has become fuzzy and interesting; disorders such as bipolar disorder and borderline personality disorder, predecessors of which were treated essentially as psychoses and subsets of insanity, are now being treated more like normal-range conditions, though they still involve a level of stigma that has mostly evaporated for conditions that are considered more normal. Second, psychiatry still treats the disorders of basically normal people as sicknesses to be cured, and CBT treats them as a set of problems to be solved. The old idea of normalcy as a lack of disorder and (for the working classes) affective flatness and reliability is mostly outmoded. In its place, there is a new idea of the normal in which normalcy itself is seen as a site of many possible disorders, and these disorders are sicknesses or problems to be managed. Third, the line between the normal and the abnormal repeatedly appears as a problem for critics of the current system of diagnosis and treatment. This is clear in the persistent worry that DSM categories and contemporary mental health practice are pathologizing normal emotional states, as in Horwitz and Wakefield's The Loss of Sadness.

The precise nature of this new normal needs to be specified. The person suffering from a mental disorder is not necessarily outside the boundaries of what is considered normal, healthy social functioning; he may simply be understood as not functioning in an optimum, productive manner. This is related to the proliferation of categories such as mental health and wellness as positive, preventative categories which in their ambition at least go beyond the pathologization and cure of specific disorders. Instead of flat, empty normality, we get an image of well-tuned, affectively engaged, optimum normality and a personality that is enhanced for productivity.

Canguilhem cites Ey, via Minkowski:

This normal man is not a mean correlative to a social concept, it is not a judgment of reality but rather a judgment of value; it is a limiting notion which defines a being's maximum psychic capacity. There is no upper limit to normality. (Canguilhem 119) 
The problem of the "upper limit of normality" in psychology had really only been suggested when Minkowski wrote this in the 1930s. Only in the contemporary era has the upper limit of normality become a central preoccupation of psychiatry and mental healthcare in general, a problem which is now being extended to broader and broader ranges of society.

The new normal suggests the emergence of a late modern form of selfhood with the following principles:

1. Mood is a ubiquitous, diverse, and insidious aspect of everyone's experience.

2. Everyone's mood needs to be regulated or managed.

3. Everyone should take responsibility for regulating or managing her own mood.

4. Techniques of mood management such as pharmaceuticals, psychotherapy, and alternative forms of stress reduction and meditation are legitimate, non-stigmatized tools of moodregulation.

5. Everyone (who's anyone) should have access to these techniques.

6. A corollary: there is no difference in kind between normal people whose moods are regulated or self-regulated without these specific tools and normal people whose moods are regulated / self-regulated with these tools. The binary becomes redefined as: those who are able, with the use of whatever tools at their disposal, to be regulated / to self-regulate and achieve a baseline state of normalcy or functionality, who are able to and should continue to progress toward optimal normalcy, vs. those who are not able to achieve a state of baseline functionality, whose dysfunctions rise to the level of psychosis or debilitation.

In the current profusion of techniques of self-care, a series of modifications to normality occur which are not directly conditioned by a relationship with abnormality. To be sure, the specter of the abnormal will have already constituted a field of the normal. But the possibility of mental and emotional disorders and, in turn, mental and emotional health, which beyond a mere lack of disorder now become a positive terrain for the pursuit of excellence, means that the normal becomes a terrain of manipulation, self-care, and management.

Despite the democratic premise of this new normalcy, it is articulated very differently across a spectrum of social groups. At the top 
end, a normative class ${ }^{5}$ constitutes mental wellness as a pursuit of excellence. For symbolic and affective workers in the mid-range of autonomy and authority, some use of these same techniques of self-care is suggested, with all the ambiguities the notion of suggestion can contain. And for affective and bodily-subjective workers whose work is largely stripped of autonomy in a form of subjective Taylorism, conformity to a fine-tuned emotional norm is imposed without a great deal of subtlety and with a good deal of coercion.

For most of the modern era even up through the era of psychoanalysis, depression and the neuroses were considered private problems. Much has been made of psychoanalysis as a form of confession, but it is still a private confession. With destigmatization, mood management, and the notion of the mood disorder as a potentially very widespread problem affecting a significant minority of people if not a plurality over the course of their lives, we get a newly public notion of depression as the cultivation of productive, affiliative, optimum normalcy. ${ }^{6}$

\footnotetext{
${ }^{5}$ See the fascinating suggestions of Canguilhem, 246: "It could be said in another way by trying to substitute an equivalent for the Marxist concept of the ascending class. Between 1759, when the word "normal" appeared, and 1834 when the word "normalized" appeared, a normative class had won the power to identify - a beautiful example of ideological illusion - the function of social norms, whose content it determined, with the use that that class made of them." We might productively consider the specific function of a normative class and normative functions within a broad array of the activity of leading social groups. Or, put another way, what are the relationships in given historic situations between hegemony and normativity?

${ }^{6}$ I would like to gratefully acknowledge Prince Mohammad Bin Fahd University for the space and resources that enabled me to edit and revise this article.
} 


\section{Works Cited}

American Psychiatric Association. "Highlights of Changes from DSM-IVTR to DSM-5.” Web. 2 May 2013.

—. "The Organization of DSM-5.” Web. 17 Jan. 2013.

BARKER, Kristin. "Self-Healing in Late-Modernity: The Case of Mindfulness." Paper presented at the annual meeting of the American Sociological Association, New York. 11 Aug. 2007. N.p.

BLAZER, Dan G. The Age of Melancholy: "Major Depression" and Its Social Origins. New York: Routledge, 2005.

BRAUSER, Deborah. "NIMH, APA Clash Over Upcoming DSM-5.” Medscape Medical News. Web. 7 May 2013.

CANGUILHEM, Georges. The Normal and the Pathological. New York: Zone Books, 1991.

CUSHMAN, Philip and Peter GILFORD. "Will Managed Care Change Our Way of Being?” American Psychologist 55, no. 9 (2000): n. pag.

DIOGENES OF SINOPE. “Suffering from Capitalism?” Dystopia Earth. Web. 7 March 2012.

Division of Clinical Psychology. British Psychological Society. "DCP Position Statement on Classification: Time for a Paradigm Shift in Psychiatric Diagnosis." Web. 1 May 2013.

EHRENBERG, Alain. The Weariness of the Self: Diagnosing the History of Depression in the Contemporary Age. Montreal \& Kingston: McGill-Queen's University Press, 2010.

FORGAS, Joseph P. "Managing Moods: Toward a Dual-Process Theory of Spontaneous Mood Regulation," Psychological Inquiry 11, no. 3 (2000): 172.

HORWITZ, Allan V. and Jerome C. WAKEFIELD. The Loss of Sadness: How Psychiatry Transformed Normal Sorrow into Depressive Disorder. Oxford: Oxford University Press, 2007.

IMS Institute for Healthcare Informatics. "The Use of Medicines in the United States: Review of 2010 Report.” Web. 1 Sept. 2013.

KIRK, Stuart and Herb KUTCHINS. The Selling of DSM: The Rhetoric of Science in Psychiatry. New York: Aldine de Gruyter, 1992. 
LEWIS, Bradley. Moving beyond Prozac, DSM, and the New Psychiatry: the Birth of Postpsychiatry. Ann Arbor: University of Michigan Press, 2006.

MARTIN, Emily. Bipolar Expeditions: Mania and Depression in American Culture. Princeton: Princeton University Press, 2007.

MARTIN, Lorna and Edward HELMORE. “Now, Don't Tell Me about Your Parents." The Observer. Web. 18 Feb. 2006.

MAYES, Rick and Allan V. HORWITZ. "DSM-III and the Revolution in the Classification of Mental Illness." Journal of the History of the Behavioral Sciences 41, no. 3 (2005): 249-267.

Mental Health America. "Ranking America's Mental Health: An Analysis of Depression across the States." Web. 1 Nov. 2007.

NORDEN, Michael. Beyond Prozac: Brain-Toxic Lifestyles, Natural Antidotes, and New-Generation Antidepressants. New York: HarperCollins, 1997.

OED Online. "mood, n.1." June 2013. Oxford University Press. Web. 1 Sept. 2013.

PARKER, Gordon, M.D., Ph.D., D.Sc, F.R.A.N.Z.C.P.; Kay ROY, B.A.; Kay Wilhelm, M.D., F.R.A.N.Z.C.P.; and Philip MITCHELL, M.D., F.R.A.N.Z.P. "Assessing the Comparative Effectiveness of Antidepressant Therapies: A Prospective Clinical Practice Study.” Journal of Clinical Psychiatry 62 (2001): 117-125.

PHILIPSON, Ilene. On the Shoulders of Women: The Feminization of Psychotherapy. New York: Guilford Press, 1993.

SHORTER, Edward. "How Prozac slew Freud," American Heritage 49, no. 5 (1998). Web. 1 Sept. 2013.

SICHERMAN, Barbara. "The Uses of a Diagnosis: Doctors, Patients, and Neurasthenia." Journal of the History of Medicine and Allied Sciences 32, no. 1 (1977): 33-54.

SMITH, Brendan L. "Inappropriate Prescribing." Monitor on Psychology 43, no. 6 (June 2012). Web. 1 Sept. 2013.

WAKEFIELD, Jerome C. "Disorder as Harmful Dysfunction: A Conceptual Critique of DSM-III-R's Definition of Mental Disorder," Psychological Review 99, no. 2 (1992): 232-247. 
ZISOOK, Sidney, MD and M. Katherine SHEAR, MD. "Guest Editorial: This Issue: Bereavement, Depression, and the DSM-5." Psychiatric Annals 43, no. 6 (June 2013): 252-254. 